\title{
The $\operatorname{ArI}_{2}$ (ion-pair states) van der Waals complexes
}

\author{
V.V. Baturo, I.N. Cherepanov, S.S. Lukashov, S.A. Poretsky, A.M. Pravilov* \\ Department of Physics, Saint-Petersburg State University, SPbSU, 7/9 Universitetskaya nab., 199034 St. Petersburg, Russia
}

\section{A R T I C L E I N F O}

\section{Article history:}

Received 10 December 2015

In final form 19 January 2016

Available online 25 January 2016

\begin{abstract}
A B S T R A C T
$\operatorname{The~} \mathrm{Arl}_{2}\left(E 0_{\mathrm{g}}^{+}\right)$van der Waals complexes have been observed and studied for the first time. Analysis of the luminescence excitation spectra as well as luminescence spectra themselves in the spectral ranges, where the $\mathrm{I}_{2}\left(E 0_{\mathrm{g}}^{+} \rightarrow B 0_{\mathrm{u}}^{+}, D 0_{\mathrm{u}}^{+} \rightarrow X 0_{\mathrm{g}}^{+}, \beta 1_{\mathrm{g}} \rightarrow A 1_{\mathrm{u}}\right.$ and $\left.D^{\prime} 2_{\mathrm{g}} \rightarrow A^{\prime} 2_{\mathrm{u}}\right)$ transitions can occur, has been carried out. It has been shown that the $\mathrm{I}_{2}\left(D \rightarrow X, \beta \rightarrow A\right.$ and $\left.D^{\prime} \rightarrow A^{\prime}\right)$ luminescence is due to $\operatorname{ArI}_{2}(E \leftarrow B)$ transitions with subsequent predissociation. We have determined the spectroscopic parameters of the $\operatorname{ArI}_{2}\left(E, v_{\mathrm{E}}=0-3\right)$ complexes.

It has been shown that rate of vibrational predissociation is $\sim 10$ times less than total rate of the $\operatorname{ArI}_{2}\left(E, v_{\mathrm{E}}=0-3\right) \rightarrow \operatorname{Ar}+\mathrm{I}_{2}\left(D, \beta, D^{\prime}\right)$ electronic predissociation.
\end{abstract}

(c) 2016 Elsevier B.V. All rights reserved.

\section{Introduction}

Spectroscopic characteristics and dynamics of rare gas-diatomic halogen van der Waals (vdW) complexes have been studied in numerous experimental and theoretical works (see [1-12] and references therein) since pioneering work of Smalley et al. [13] (see [14] and references therein, also). This is largely because the complexes have proven to be theoretically tractable model systems for understanding weakly-bound coupling in molecular species and unimolecular reaction dynamics. Dissociation energies, lifetimes, quantum yields of luminescence of vibrational predissociation products of the homonuclear halogen vdW complexes, $\mathrm{RgHal}_{2}$, and $\mathrm{RgICl}$ valence state vdW complexes, as well as frequencies of vdW modes, have been determined experimentally (see [1-17] and references therein). Detailed theoretical analysis of potential energy surfaces (PESs) of the complexes and their dynamical behavior have been carried out, also (see $[5,7,18]$ and references therein).

The $\mathrm{RgHal}_{2}$ valence state complexes undergo fast vibrational and electronic predissociation (VP and EP, respectively), so, e.g., lifetime of the $\operatorname{ArI}_{2}\left(\mathrm{BO}_{\mathrm{u}}^{+}, v_{\mathrm{B}}\right) \mathrm{vdW}$ complexes, $\tau<80 \mathrm{ps}$ (see [5] and references), is much less than its radiative lifetime $(\sim 1 \mu \mathrm{s})$, if one suppose that it is close to that of free (isolated) $I_{2}(B)$ molecule (here and further a subscript in $v_{\mathrm{B}}$ etc. means to which state this vibronic level belongs). To the best of our knowledge, the only exception is $\operatorname{NeICl}\left(A^{3} \Pi_{1}, v_{\mathrm{A}}=12-15\right)$ complex, $\tau=3 \pm 2 \mathrm{~ns}$ for $v_{\mathrm{A}}=14$ [19]. Therefore, nobody observed luminescence of the $\mathrm{RgHal}_{2}$ valence state

\footnotetext{
* Corresponding author.

E-mail address: a.pravilov@spbu.ru (A.M. Pravilov).
}

complexes. Luminescence of products of vibrational predissociation $\left(\operatorname{Hal}_{2}\left(B, v_{\mathrm{B}}\right), v_{\mathrm{B}}^{\prime}<v_{\mathrm{B}}\right)$ has been observed, only.

Meanwhile, ion-pair (IP) states of halogen molecules, especially iodine, provide a more promising system for studies dynamics in vdW complexes than those in the valence states, correlating with the second dissociation limit, $\mathrm{I}_{2}(B)$, for example. It is due to the fact that IP states are arranged in four narrow manifolds (tiers) nested by similar potential energy curves that form a very dense rovibronic structure (see [20] and references therein). The first IP tier consists of six states of distinct symmetries, namely, $D^{\prime} 2_{\mathrm{g}}, \beta 1_{\mathrm{g}}, D 0_{\mathrm{u}}^{+}, E 0_{\mathrm{g}}^{+}$, $\gamma 1_{\mathrm{u}}$, and $\delta 2_{\mathrm{u}}$, in order of increasing $T_{\mathrm{e}}$.

To populate the complexes of the IP states, one can utilize usual pump-probe technique (see $[3,6,11]$ and references). There are only several papers devoted to these complexes. The $\mathrm{HeI}_{2}(E)$ complex has been observed in [7]. Luminescence in the $\lambda_{\text {lum }}=338-345 \mathrm{~nm}$ spectral range, where $\mathrm{I}_{2}\left(\beta 1_{\mathrm{g}} \rightarrow A 1_{\mathrm{u}}\right.$ and $\left.D^{\prime} 2_{\mathrm{g}} \rightarrow A^{\prime} 2_{\mathrm{u}}\right)$ transitions should be observed, was detected, whereas the probe radiation was corresponded to the $\mathrm{HeI}_{2}\left(E, v_{\mathrm{E}}=1 \leftarrow B, \nu_{\mathrm{B}}=23\right)$ spectral range. The origin of the $\mathrm{I}_{2}\left(\beta \rightarrow A\right.$ and $\left.D^{\prime} \rightarrow A^{\prime}\right)$ luminescence was not discussed. Signals were extremely low due to low lifetime of the $\mathrm{HeI}_{2}(B)$ state (see above). The $\mathrm{NeICl}\left(E 0^{+}, \beta 1\right.$ and $\left.D^{\prime} 2\right)$ complexes have been also observed and studied in transitions from long-lived $\operatorname{NeICl}\left(A, v_{\mathrm{A}}=12-15\right)$ complex [21,22].

In this letter, we report on the first observation of $\operatorname{ArI}_{2}(E) \mathrm{vdW}$ complexes.

We have observed the $\mathrm{I}_{2}(E \rightarrow B)$ and $\mathrm{I}_{2}\left(D \rightarrow X, \beta \rightarrow A\right.$ and $\left.D^{\prime} \rightarrow A^{\prime}\right)$ luminescence and shown that luminescence from the $D, \beta$ and $D^{\prime}$ states occurs due to transitions in vdW complex, $\operatorname{ArI}_{2}(E \leftarrow B)$. At some excitation bands, we have observed the $\mathrm{I}_{2}(E \rightarrow B)$ luminescence, which origin is optical transitions in vdW $\mathrm{ArI}_{2}$ complexes, also. Analysis of the excitation spectra has allowed us to assign 